\title{
Work Status of Alumni and their Satisfaction on Selected Indicators in the School of Advanced Studies (SAS)
}

\author{
Rosanna D. Gonzales ${ }^{1, *}$, Adonis S. Bautista ${ }^{1} \&$ Reynaldo T. Gelido ${ }^{1}$ \\ ${ }^{1}$ School of Advanced Studies, Pangasinan State University, Urdaneta City, Philippines \\ *Correspondence: School of Advanced Studies, Research Coordinator and Faculty, Pangasinan State University, \\ Urdaneta City, Philippines. E-mail: rosanna_gonzales0906@yahoo.com
}

Received: February 10, 2019

Accepted: March 22, 2019 Online Published: March 28, 2019

doi:10.5430/wje.v9n2p56

URL: https://doi.org/10.5430/wje.v9n2p56

\begin{abstract}
Attending graduate and post-graduate school certainly can contribute to one's development and advancement. The School of Advanced Studies in the Philippines is one of the leading institutions that caters the academic needs of professionals and employees from different fields of specialization. Every year, it produces quality graduates who had satisfactorily completed all the set requirements of their respective degree programs. Tracer studies is an avenue towards quality assurance, it serves as a way of identifying the institution's strengths, weaknesses, opportunities, and threats. This study provided an information on Alumni's profile including employment status and reason for enrolling in the said school, extent of adequacy of skills learned amd degree of satisfaction from experiences they earned while studying. It made use of the descriptive survey and appropriate statistical tool. Findings revealed that obtaining such degree is rewarding because the individual's professional value was increased hand in hand with the additional remuneration built within it and these are credited to the adequacy of skills they gained in the aspects of knowledge and technical, research, leadership, and; communication. Likewise, they received better service delivery along the learning environment particularly on teaching staff's knowledge, interaction, creativity, respect for students and delivery skills.
\end{abstract}

Keywords: advanced studies, quality assurance, tracer study, work status

\section{Introduction}

Governments of most countries across the globe allocate funds for education since it is perceived not only as a right but also a duty (Roser \& Ortiz-Ospina, 2019). In fact, education sector is prioritized because of standing in the principle that "education is an investment" (Nielsen Global Survey of Education Aspirations, 2013). Investing in education is considered as smart economics since it can put people on a path toward good health, empowerment, and employment (Brandt, 2015) aside from claiming that individual's earnings increase with education (Juster, 1975), it is also known as paving the road to better jobs, more money and improved lifestyles (Nielsen Global Survey of Education Aspirations, 2013). Further. Nielsen Global Survey of Education Aspirations (2013) study revealed that more than three-quarters (78\%) of global online respondents (29,000 internet respondents in 58 countries) agreed that receiving a higher education is important. Thus, being able to receive such is an avenue for having an employment. Once employed does not stop there because data coupled with voluminous information is continuously growing and developing, therefore; updating one's capability is considered to be of high relevance in the world of work. It can't be denied that education play a significant role in various degree programs (be it in tertiary, graduate and post-graduate level) for it contributes to the economic development of an individual, community, and to the country as a whole. It also contributes in the establishment, production and dissemination of recent knowledge and skills through instruction delivery and support services received by Alumni from an educational institution that develops their potentials (Awahnej, Sabbah, \& Naser (2017). However, it is not enough to obtain an education and be a part of the workforce since input is closely associated with the output and by considering the process aspect of an endeavor performance evaluation is necessary because the quality of higher education obtained by a student depends on fairly well-known factors such as his inputs into the study, the quantity, and quality of school inputs, the effectiveness of the curriculum and teaching method (Buenvinida \& Yazon, 2017). Advanced studies call for quality assurance by meeting the preset standards stipulated in the Philippines Qualifications Framework (PQF), in so doing; 
evaluating the performance of key role players and related aspects in the academic institutions is a must. Performance as defined by Caluza, Function, Verecio, Cinco, Quisumbing \& Laurente (2017) in their paper "Faculty Perfromance Evaluation in a Philippine University Information Technology Program" is the completion of a certain kind of job or an undertaking measured and evaluated against set of standards (correctness, exactness, completeness, speed and efficiency) as a result of activities of an individual or organization over a period of time. They also cited that performance and success are based on the perceived knowledge in the execution of a task. Such performance may be determined through the tracer studies and satisfaction surveys, hence; such a study.

\subsection{Questions of the Study}

To gather valuable information about the employment data, adequacy of skills learned/gained and degree of satisfaction of graduates received from one's institution, follow-up studies is very much applicable (Gonzales, Gelido, Bautista, Jarin, \& Lumanta, 2017) since it will reveal whether the graduate school is responsive, relevant and appropriate to the present needs of the time as to study conditions (learning environment and facilities), services (service areas and service providers) and desired quality (as reflected in the profile and employment data) of alumni (Awajneh, Sabbah, \& Naser, 2017). Tracer studies will promote development and incorporate effective improvements into institutional programs. With the information collection and analysis of alumni (graduate and post-graduate students) work-status and satisfaction on study experiences (Badiru \& Wahome, 2016) at Pangasinan State University-School of Advanced Studies, Philippines.

Specifically, this study tries to answer the following questions:

1. What is the work-status of Pangasinan State University-School of Advanced Studies (PSU-SAS) alumni along:
a. personal-professional profile, and;
b. work-status (employment/promotion)?

2. What is the extent of adequacy of the skills learned by the respondents (PSU-SAS alumni) in terms of:
a. knowledge and technical,
b. communication,
c. human relations,
d. leadership,
e. research,
f. problem solving,
g. Information and Communication, and;
h. Technology?

3. What is the degree of satisfaction of the respondents on the following selected indicators:
a. general services,
b. learning environment, and;
c. facilities?

\subsection{Importance of the Problem}

Oftentimes, tracer studies are conducted in the undergraduate levels only, however; with the advent of accreditation and quality assurance in the graduate and post-graduate education to meet set standards in the academe (advanced studies) is deemed necessary to show and have check-balance between input-process-output and outcome. According to McInis (2002) performance evaluation together with its effectivity is an aid in improving learning outcomes regardless of the nature and level of the program. Hand in hand with the evaluation is the assessment of institution's aggregate related service delivery indicators which can be of help in determining whether the key service areas or providers meet the expectations of the people they serve (students/alumni) from the academic stand point in terms of skills development and service delivery (Miller, 1987). This study aims to determine performance of the school of advanced studies as perceived by its students/alumni in terms of the extent of adequacy of skills provided to them and their degree of satisfaction along selected indicators. It is the expected that to some extent upon the completion of such study, issues and concerns may be addressed particularly on the areas needing improvement and sustain the operation of the aspects at par excellent over the others. The theory of performance (ToP), career development model 
and the input-process-output-outcome (IPOO) model are behind this study. the quality of performance received by an alumni/graduate from a particular academic institution may have a positive or negative effect as to the quality of its products. The three frameworks suggest that the work-status and perceived satisfaction of alumni from the school of advanced studies as to skills learned/gained and from the received selected delivery indicators be evaluated because it is believed that as an individual advances his levels of performance by attending graduate and post graduate studies, one is able to produce deeper levels of learning, improved levels of skills development and more connection with the discipline for larger classes while spending less time doing it (Elger, D., nd).

\subsection{Related Literature and Studies}

Included in this portion are some of the data thematically presented that are of relevance to the study being conducted.

\subsubsection{Career Development Theory}

Diem \& Ha (2013) claimed that there are some theories that can explain one's work-status Among the theories include: 1) theory of Trait \& Factor which suggests that the career choice is based on factors such as: accurate knowledge on oneself, thorough knowledge of job specification and the ability to make a proper match between the two wherein the closer the match of personality to job, the greater the job satisfaction and level of career success; 2) Ginzberg, Ginsburg, Axelrad and Herma theory also stated that the career choice was influenced by four factors namely: a) practical factors, b) influence of the educational, c) emotional factors, and; d) personal values; 3) Holland's career typology mentioned that individuals are attracted to a particular occupation that meets their personal needs and provides them satisfaction. and; 4) social cognitive career theory explained that career choice is affected by beliefs that the individual develops and refines through four main sources: a) the personal performance accomplishments, b) vicarious learning, c) social persuasion, as well as; d) physiological states and reactions. These theories explained that the current job is the result of individuals' selection, accumulation, analysis, synthesis and decision progress formed from childhood to present and are influenced and impacted by external and internal factors. Therefore, the current employment situation of the respondents is not only affected by the educational process obtained from institutions, but also it is affected by a previous process. At the beginning, if students have not yet chosen a suitable career options, consistent to their interests and personality, they are unlikely to be satisfied with the current job. This indirectly reduces the possibility of having a suitable job.

\subsubsection{Skills Gap}

Coy (2014) published a research from a platform for online courses revealed that employees are unsatisfied with their capabilities as they relate to their current jobs. In the survey, 61 percent of participants said that they feel the presence of skills gap, while 54 percent said that they don't know everything they need to know to perform their work. Technical skills are the most in demand. Of participants who need more skills for their current roles, 33 percent said they lacked technical expertise like computer programming and software skills. Management skills were the second most sought after. It was claimed that problems root from the gap in what students learn and the knowledge they use on the job. Almost half of survey participants said that their higher education helped them land their first job, more than one third said they use less than 10 percent of what they learned in college in the workplace. "The data also shows that while higher education may be effective at helping individuals score their first job, skills and knowledge learned at academic institutions become obsolete so every academic institution should set unique skills to be developed by their students/alumni just like how the Americans change professions and skill-set requirements change,"

\subsubsection{Student Satisfaction}

In the study conducted by Wei \& Ramalu, (2011) Customer satisfaction (CS) is defined as "a cognitive or affective reaction that emerges in response to a single or prolonged set of service encounters." Regardless of how customer satisfaction is measured, it is proven that a satisfaction received from service providers will exhibit loyalty and provide positive result. In the context of learning institution, the student/alumni/graduate satisfaction plays an important role in determining the originality and accuracy of the education system. This is because the higher the level of satisfaction rated by the respondent to a certain service encounter, the better. Wei \& Ramalu (2011), cited that that if an institution possesses essential educational facilities with effective teaching and training staff, the student will most likely be more motivated, loyal and good performers in their academic.

\subsubsection{Service Quality}

In the study of Wei \& Ramalu (2011), service quality (SQ) is defined as a focused evaluation that reflects the customer's perception of specific dimensions of services provided. The particular perception towards the dimensions 
of services is influenced by several factors which includes the quality of the services received from service providers The Service Quality (SERVQUAL) model as indicated in the study of Wei and Ramalu (2011) is a multi-item scale developed to assess customer perceptions of service quality in service and retail. It consists of ten dimensions namely: i. reliability (service-delivery), ii. responsiveness (response), iii. competence (knowledge and skill), iv. Access (convenience), v. courtesy (staff-attitude), vi. communication (information), vii. credibility (staff-attitude), viii. security (safety, ix. understanding of customer (service-oriented), and; x. tangible (facilities).

The present study is somehow related on the abovementioned indicators, however; vary in the main instrument used, locale of the study, respondents and stipulated problems to be answered.

\subsection{Limitations of the Study}

The study was not able to include Alumni who are working outside region 1in the Philippines.

\section{Method and Procedures}

The descriptive survey design and analytical approach was used in this study due to its appropeiateness and suitability.

\subsection{Population and Sample}

The respondents were the alumni/graduates of PSU-SAS in MAEd, Ph.D. and EdD programs from AY 2013 - 2017. Purposive sampling was used wherein personal administration of the questionnaire was utilized. A total of 89 respondents from various degree programs were involved.

\subsection{Instruments of the Study}

The instrument used in the study was patterned/adapted from the study of Buenvinida \& Yazon (2017), and; Gonzales, Gelido, Bautista, Jarin, \& Lumanta (2017). Part I of the questionnaire contains the profile of the respondents (degree, civil status, sex); Part II was on the extent of adequacy of skills learned while part III was on their degree of satisfaction on selected indicators (general services, learning environment and facilities).

\subsection{Statistical Analysis}

Frequency counts, percentages, ranking, weighted means were used as the statistical tools in Alumni's profile and other related variables, employment/promotion status. On the other hand, the adequacy of skills learned from their institution and degree of satisfaction on services, learning environment, and facilities were evaluated using the rating system 4-Highly Adequate/Highly Satisfied; 3 Adequate/ Satisfied; 2-Moderately Adequate/Moderately Satisfied; and 1-Inadequate/Least Satisfied. The weighted means of the four-point scale for the adequacy of skills learned, and the degree of satisfaction on services were interpreted using the scheme: 3.50-4.00 (Highly Adequate/Highly Satisfied); 2.50-3.49 (Adequate/Satisfied), 1.50-2.49 (Moderately Adequate/Moderately Satisfied; and 1.00 -1.49 (Inadequate/ Least Satisfied).

\section{Results and Discussion}

The following discussions present the data based on the stated objectives of the study.

\subsection{On Profile, Employment Status and Reason for Enrolling a Graduate or Post-Graduate Education}

Tables 1 shows the profile of respondents in terms of their: a) degree, b) civil status, and; c) sex while tables 2-4 presents the employment status particularly on salary grade, promotion and wait-time for promotion. On the other hand, table 5 reflects the reason of the Alumni in enrolling such degree programs in the School of Advanced Studies. 


\subsection{On Profile}

Table 1. Profile of the Respondents

\begin{tabular}{|c|c|c|c|c|c|c|c|c|}
\hline \multirow[t]{2}{*}{ Profile } & \multicolumn{2}{|c|}{ EdD } & \multicolumn{2}{|c|}{ PhD } & \multicolumn{2}{|c|}{ MAEd } & \multirow{2}{*}{$\overrightarrow{0}$} & \multirow[t]{2}{*}{$\%$} \\
\hline & f & $\%$ & f & $\%$ & $\mathbf{F}$ & $\%$ & & \\
\hline Degree & 20 & 22 & 8 & 9 & 61 & 69 & 89 & 100 \\
\hline \multicolumn{9}{|l|}{ Civil Status } \\
\hline Single & 2 & 10 & 3 & 4 & 28 & 46 & 33 & 37 \\
\hline Married & 18 & 90 & 5 & 60 & 32 & 52 & 55 & 62 \\
\hline Separated & 0 & $\mathbf{0}$ & 0 & 0 & 1 & 2 & 1 & 1 \\
\hline \multicolumn{9}{|l|}{ Sex } \\
\hline Male & 7 & 8 & 5 & 6 & 23 & 26 & 35 & 39 \\
\hline Female & 13 & 15 & 3 & 3 & 38 & 43 & 54 & 60 \\
\hline
\end{tabular}

\section{a. Degree}

More than half of the Alumni (table 1) came from Master of Arts in Education (MAEd) degree program with 61 or $69 \%$. This can be attributed to the many fields of specialization (Mathematics, Science, Filipino, Social Studies, Guidance and Counseling, Special Education, English, Technology, and Livelihood Education, Educational Management) under this program which might have attracted them to enroll in the institution. It was followed by Doctor of Education (EdD) with 20 or 22 percent. It may also be associated with the three fields of specialization within it (Guidance and Counseling, Mathematics and Educational Management). The degree program with the least number of respondents was Doctor of Philosophy (Ph.D.) major in Development Studies with 8 or 9\%. This probably implies that the number of major (specialization) can increase the number of alumni in a particular degree program.

\section{b) Civil Status}

In terms of civil status, $60 \%$ of the Alumni were married across the three-degree programs: EdD with 20\%, Ph.D. (32\%) and MAEd (36\%) compared to the single with less than 50\%. This result is contrary to the results of previous studies conducted in the undergraduate degree programs [Gonzales, Gelido, Bautista, Jarin, \& Lumanta, 2017)]. This may mean that the alumni were in their mid-adulthood stage where having a stable job may influence an individual to consider a family life whom one may call his own.

$$
\text { c. Sex }
$$

The Alumni are composed of females with 54 or $60 \%$ twice higher than males with 35 or $39 \%$. This result is supported by the common knowledge that teaching is a female-dominated profession because of their nurturing and maternal ability [11]. This finding also supports the previous study about the role of female teachers in increasing the literacy rate and their increased career satisfaction (Buenvinida \& Yazon, 2017).

\subsection{On Employment Status}

Table 2. Distribution of the Alumni in Terms of Salary Grade

\begin{tabular}{|c|c|c|c|c|c|c|c|c|}
\hline \multirow{2}{*}{$\begin{array}{l}\text { Salary } \\
\text { Grade } \\
\text { (SG) }\end{array}$} & \multicolumn{2}{|c|}{ EdD } & \multicolumn{2}{|c|}{ PhD } & \multicolumn{2}{|c|}{ MAED } & \multirow{2}{*}{$\frac{\frac{\vec{\theta}}{\hat{\theta}}}{f}$} & \multirow{2}{*}{$\%$} \\
\hline & f & $\%$ & f & $\%$ & $\mathbf{F}$ & $\%$ & & \\
\hline 11 & 1 & 5 & & $\mathbf{0}$ & 8 & 13 & 9 & 10 \\
\hline 12 & 2 & 10 & 0 & 0 & 7 & 11 & 9 & 10 \\
\hline 13 & 2 & 10 & 1 & 13 & 24 & 40 & 27 & 30 \\
\hline 14 & & & & $\mathbf{0}$ & 4 & 7 & 4 & 5 \\
\hline 15 & 7 & 35 & 3 & 37 & 13 & 21 & 23 & 26 \\
\hline 16 & 7 & 35 & 3 & 37 & 5 & 8 & 15 & 17 \\
\hline 17 & 1 & 5 & 1 & 13 & 0 & 0 & 2 & 2 \\
\hline
\end{tabular}

The result reflected that since the bulk of Alumni are in their master's degree, it confirms that most of them 27 or $30 \%$ of them received a salary grade of 13 . This is due to the reason that most of the alumni-respondents are still taking their MAEd degree programs. 
Table 3. Promotion Status of Alumni

\begin{tabular}{|c|c|c|c|c|c|c|c|c|}
\hline \multirow[t]{2}{*}{ Have you been Promoted } & \multicolumn{2}{|l|}{ EdD } & \multicolumn{2}{|l|}{ PhD } & \multicolumn{2}{|c|}{ MAED } & \multirow{2}{*}{$\begin{array}{l}\overrightarrow{0} \\
\mathbf{f}\end{array}$} & \multirow[t]{2}{*}{$\%$} \\
\hline & f & $\%$ & $\mathbf{F}$ & $\%$ & f & $\%$ & & \\
\hline Yes & 20 & 100 & 8 & 100 & 60 & 98 & 88 & 99 \\
\hline No & 0 & $\mathbf{0}$ & 0 & $\mathbf{0}$ & 1 & 2 & 1 & 1 \\
\hline
\end{tabular}

It can be gleaned in table 3 that 88 out of $89(99 \%)$ of the Alumni are promoted. This contradicts the claim of Juster (1975) stating that the systematic differences in earnings may not be due solely to differences in educational attainment of the high probability of being promoted if educational achievement is improved. However, it is associated to the theory of Trait \& Factor which suggests that the career choice is based on factors such as: accurate knowledge on oneself, thorough knowledge of job specification and the ability to make a proper match between two wherein the closer the match of personality to job, the greater the job satisfaction and level of career success (Diem \& Ha, 2013).

Table 4. Wait-time of Promotion for Alumni

\begin{tabular}{|c|c|c|c|c|c|c|c|c|}
\hline \multirow{2}{*}{ Wait-time for Promotion } & \multicolumn{2}{|c|}{ EdD } & \multicolumn{2}{|l|}{ PhD } & \multicolumn{2}{|c|}{ MAED } & \multirow{2}{*}{$\begin{array}{l}\vec{\theta} \\
\mathbf{0} \\
\mathbf{f}\end{array}$} & \multirow[t]{2}{*}{$\%$} \\
\hline & f & $\%$ & f & $\%$ & f & $\%$ & & \\
\hline Less than a month & 3 & 15 & & & 10 & 16 & 13 & 15 \\
\hline 1 to 6 months & 2 & 10 & 1 & 10 & 5 & 8 & 8 & 8 \\
\hline 7 to 11 months & 6 & 30 & 2 & 20 & 1 & 2 & 9 & 10 \\
\hline 1 year to less than 2 years & 3 & 15 & 1 & 10 & 17 & 27 & 21 & 24 \\
\hline 2 years to less than 3 years & 3 & 15 & 2 & 20 & 24 & 45 & 29 & 33 \\
\hline 3 years to less than 5 years & 3 & 15 & 2 & 20 & 2 & 2 & 9 & 10 \\
\hline
\end{tabular}

The table shows that the alumni are promoted after two years to less than 3 years. It implies that the completion of academic requirements or degree can be contributory to the wait-time period for the promotion of the Alumni.

3.4 On Enrolment Reason

Table 5. Reason of Alumni in Enrolling at PSU-SAS

\begin{tabular}{|c|c|c|c|}
\hline Reasons & $\begin{array}{l}\text { EdD } \\
\text { (rank) }\end{array}$ & $\begin{array}{l}\text { PhD } \\
\text { (rank) }\end{array}$ & $\begin{array}{l}\text { MAED } \\
\text { (rank) }\end{array}$ \\
\hline 1. Prospect for Career Advancement and Affordable Tuition Fee & 3 & & \\
\hline 2. School Location, Career Advancement, and Affordable Tuition Fee & 2 & & \\
\hline $\begin{array}{l}\text { 3. School Location, Personal Prestige, Career Advancement, Affordable } \\
\text { Tuition Fee }\end{array}$ & & 2 & 3 \\
\hline $\begin{array}{l}\text { 4. School Location, Personal Prestige, Availability of Degree Program } \\
\text { Desired, and Affordable Tuition Fee }\end{array}$ & & 3 & \\
\hline $\begin{array}{l}\text { 5. School Location, Career Advancement, Availability of Degree Program } \\
\text { Desired, and Affordable Tuition Fee }\end{array}$ & 1 & 1 & 1 \\
\hline
\end{tabular}

The Alumni enrolled to PSU-SAS due to the School Location, Career Advancement, Availability of Degree Program Desired, and Affordable Tuition Fee. This implies that these factors are of relevance to students.

3.5 On Extent of Adequacy of Skills Learned

The extent of adequacy of the skills learned of the Alumni was shown in table 6 . 
Table 6. Extent of Adequacy Skills Learned

\begin{tabular}{lllllll}
\hline Skills & $\begin{array}{l}\text { EdD } \\
\text { Mean }\end{array}$ & $\begin{array}{l}\text { PhD } \\
\text { Mean }\end{array}$ & $\begin{array}{l}\text { MAEd } \\
\text { Mean }\end{array}$ & $\begin{array}{l}\text { Weighted } \\
\text { Mean }\end{array}$ & VD & Rank \\
\hline Knowledge and Technical & 3.62 & 3.57 & 3.74 & 3.64 & HA & $\mathbf{1}$ \\
Communication & 3.40 & 3.45 & 3.65 & 3.5 & HA & $\mathbf{5}$ \\
Human Relations & 3.56 & 3.60 & 3.45 & 3.53 & HA & $\mathbf{4}$ \\
Leadership & 3.70 & 3.58 & 3.35 & 3.54 & HA & $\mathbf{3}$ \\
Research & 3.53 & 3.70 & 3.60 & 3.61 & HA & $\mathbf{2}$ \\
Problem Solving & 3.24 & 3.50 & 3.46 & 3.4 & A & $\mathbf{7 . 5}$ \\
Information and Communication & 3.46 & 3.36 & 3.55 & 3.45 & $\mathbf{A}$ & $\mathbf{7 . 5}$ \\
Technology & 3.39 & 3.40 & 3.38 & 3.45 & $\mathbf{A}$ & $\mathbf{8}$ \\
\hline
\end{tabular}

Results revealed that the skills learned of the Alumni in PSU-SAS were "highly adequate" along knowledge and technical skills (3.64), research skills (3.61), leadership skills, human relations skills, and communication skills. Rated as "adequate" were on information and communication (3.45), technology skills (3.45) and problem-solving skills with a weighted mean mean of 3.4. It can be attributed to the kind of instruction that they received from their respective degree programs and the teaching-learning process of their respective professors (i.e., teaching methods). This implies that institution where they obtained their respective degree programs is well-equipped with the skills that are necessary in the workplace of its Alumni and it provides adequately the most in-demand skills, i.e. the "technical skill" (Coy, 2014).

\subsection{On Degree of Satisfaction on Selected Services}

Wei \& Ramalu (2011) described service quality (SQ) as a focused evaluation that reflects the customer's perception of specific dimensions of services provided. Service quality goes together with the concept of educational quality wherein set of terms and conditions must be available in the educational process to meet and fulfill the needs of its beneficiaries (Saif, 2014). Tables 7-9 provides the degree of satisfaction of Alumni on general services, learning environment and facilities.

Table 7. Alumni's Degree of Satisfaction on General Services

\begin{tabular}{lllllcc}
\hline Services & EdD & PhD & MAEd & Weighted & VD & Rank \\
& Mean & Mean & Mean & Mean & & \\
\hline 1.Administrative Support & 3.5 & 3.21 & 3.42 & 3.39 & S & $\mathbf{9}$ \\
a. Accounting & 3.64 & 3.43 & 3.35 & 3.47 & S & $\mathbf{5}$ \\
b. Cashier & 3.64 & 3.29 & 3.33 & 3.42 & S & $\mathbf{7}$ \\
c. Admissions & 3.64 & 3.14 & 3.42 & 3.4 & S & $\mathbf{8}$ \\
d. Registrar & 3.79 & 3.43 & 3.55 & 3.59 & HS & $\mathbf{2}$ \\
2. Faculty Support & 3.79 & 3.0 & 3.56 & 3.45 & S & $\mathbf{6}$ \\
3. Staff Attitude & 3.5 & 3.29 & 3.65 & 3.48 & HS & $\mathbf{4}$ \\
4. Academic Advising & 3.5 & 3.29 & 4.12 & 3.63 & HS & $\mathbf{1}$ \\
5. Research Mentoring & 3.5 & 3.54 & 3.48 & 3.50 & HS & $\mathbf{3}$ \\
6. Food Services & 3.14 & 3.0 & 3.30 & 3.14 & $\mathbf{S}$ & $\mathbf{1 3}$ \\
7. Library Services & 3.50 & 3.29 & 3.37 & 3.38 & S & $\mathbf{1 0}$ \\
8. Extension/Outreach/ Community Involvement & 3.15 & 2.86 & 3.09 & 3.03 & S & $\mathbf{1 4}$ \\
9. Extra/Co-curricular Activity & 3.21 & 3.29 & 3.17 & 3.23 & S & $\mathbf{1 2}$ \\
10. Security & 3.50 & 3.29 & 3.23 & 3.34 & S & $\mathbf{1 1}$ \\
\hline
\end{tabular}


Table 7 shows that the Alumni are "satisfied" on most of the general services, It is interesting to note that they are "highly satisfied" on academic advising, registrar's services, research mentoring and staff attitude. It conforms with the result of Buenvinida \& Yazon (2017) except on faculty support and research mentoring.

Table 8. Alumni's Degree of Satisfaction in Terms of Learning Environment

\begin{tabular}{llllllll}
\hline Learning Environment & EdD & $\begin{array}{l}\text { PhD } \\
\text { Mean }\end{array}$ & $\begin{array}{l}\text { MAEd } \\
\text { Mean }\end{array}$ & $\begin{array}{l}\text { Weighted } \\
\text { Mean }\end{array}$ & Mean & Rank \\
\hline 1. & Teaching Staff & 3.69 & 3.43 & 3.58 & 3.56 & HS & $\mathbf{3}$ \\
1.1 & Knowledge of content & 3.75 & 3.43 & 3.62 & 3.6 & HS & $\mathbf{1}$ \\
1.2 & Interaction with students & 3.69 & 3.29 & 3.70 & 3.56 & HS & $\mathbf{3}$ \\
1.3 & Creativity in teaching & 3.77 & 3.29 & 3.64 & 3.56 & HS & $\mathbf{3}$ \\
1.4 & Delivery Skills/Teaching Methods & 3.69 & 3.14 & 3.67 & 3.5 & HS & $\mathbf{5}$ \\
2. & Instructional Materials & 3.43 & 3.29 & 3.56 & 3.42 & S & $\mathbf{6}$ \\
3. & Respect for students & 3.57 & 3.43 & 3.57 & 3.52 & HS & $\mathbf{4}$ \\
\hline
\end{tabular}

It can be gleaned in table 8 that as to Alumni's degree of satisfaction concerning learning environment, they were "highly satisfied" on all indicators stipulated under teaching staff which includes professors' knowledge of content, interaction with students, creativity in teaching, respect for students, delivery skills/teaching methods. However, they were "satisfied" in the instructional materials (3.42) utilized by their mentors. It affirms the result of the study conducted by Buenvinida \& Yazon (2017).

Table 9. Alumni's Degree of Satisfaction in on Facilities

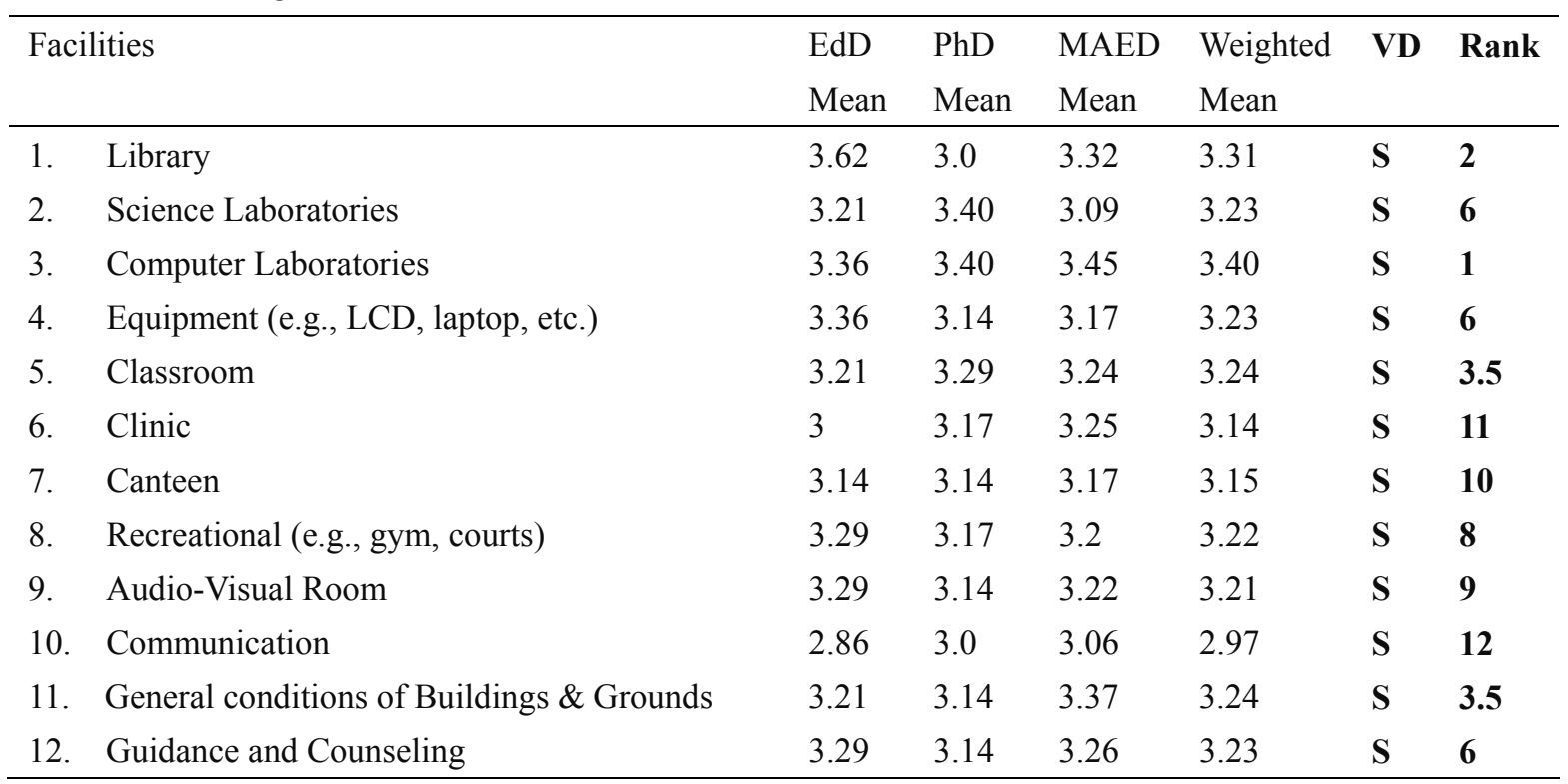

The Alumni are "satisfied" on all the identified indicators under facilities which is similar to the survey of Buenvinida \& Yazon (2017) wherein the same verbal description was received by their institution in this aspect. The data reveals that the top 4 in the list are on computer laboratories, library, classroom and general conditions of buildings and grounds while the 4 indicators that are least in the rank are communication, clinic, canteen and audio-visual room. This may affect the institution since Wei \& Ramalu (2011), cited that that if an institution possesses essential educational facilities with effective teaching and training staff, the student will most likely be more motivated, loyal and good performers in their academic. 


\section{Conclusion and Recommendations}

The work status profile of PSU-SAS Alumni improved as they acquire higher level of learning as reflected in their promotion status due to the adequate skills that they received while studying associated with the very good learning environment that developed their unique potentials. Great care and attention on the average level of satisfaction received by the institution on all facilities should be considered in order to have better delivery of services. The institution's development plan should be revisited as to the extent of the implementation along facilities. Continuous performance evaluation should be conducted and a sequel of this study focusing on the employer's feedback and job satisfaction is a must with inclusion of the Alumni working outside the region 1and so with those employed in other countries .

\section{References}

Awajneh, A. M. H., Sabbah, S. S. M., \& Naser, I. A. S. (2017). Concepts and roles of faculty in the Palestinian Universities in the light of knowledge economy. World Journal of Education, 7(6), 80-89. https://doi.org/10.5430/wje.v7n6p80

Badiru, E, O., \& Wahome, M. (2016). Conducting graduate tracer studies for quality assurance in East African. Universities: A focus on graduate students voices on quality culture. Journal of Education and Practice, 7(6), 174-181.

Brandt, Yoka. (2015). Education: the most powerful investment in our future. UNICEF. https://blogs.unicef.org/ blog/education-the-most-powerful-investment-in-our-future/

Buenvinida, L. P., \& Yazon, A. D. (2017). Assessment of graduates of Master of Arts in Education (MAED) in one State University in the Philippines. Asia Pacific Journal of Multidisciplinary Research, 5(2), 77-86.

Coy, C. (2014). In the news: for employees, skills gap is all to real. Retrieved from: https://www.cornerstoneondemand. com/rework/news-employees-skills-gap-all-too-real

Diem, P. T., \& Ha, N. M. (2013). Analysing the employment status of graduate students: the case of Kent International college in Vietnam. Advances in Management \& Applied Economics, 3(4), 235-248.

Elger, D. (nd). Theory of performance. Retrieved 7/18/2017 from https://www.webpages.uidaho.edu/ele/scholars/Results/Workshops/Facilitators_Institute/Theory\%20of\%20Perf ormance.pdf

Gonzales, R. D., Gelido, R. T., Bautista, A. S., Jarin, S. A., \& Lumanta, C. N. (2017). Employers feedback on graduates of Pangasinan State University, Philppines. International Journal of Scientific \& Engineering Research, 8(9), 1151-1161.

Juster, Thomas. (1975). Education, income and human behavior. National Bureau of Economic Research ISBN 0-07-010068-3 (p.95).

McInnis, C. (2002). The impact of technology on faculty performance and its evaluation. New directions for institutional research, 2002(114), 53-62. https://doi.org/10.1002/ir.46

Miller, R. I. (1987). Evaluating faculty for promotion and tenure. The Jossey Bass Higher Education Series. Jossey-Bass Publishers, 350 Sansome Street, San Francisco, CA 94104.

Nielsen Global Survey of Education Aspirations. (2013). Education is an investment for the future around the world. Retrieved from https://www.nielsen.com/cn

Roser, M., \& Ortiz-Ospina. (2019). Financing education. Published online at OurWorldInData.org. Retrieved from: https://ourworldindata.org/financingeducation [Online Resource].

Saif, N. I. (2014). The effect of service quality on student satisfaction: A field study for health services administration Students. International Journal of Humanities and Social Science, 4(8).

Wei, C. C., \& Ramalu, S. S. (2011). Students satisfaction towards the University: does service quality matters? International Journal of Education, 3(2), E15. 